\title{
PENGARUH KARAKTERISTIK SOSIAL EKONOMI TERHADAP PRODUKSI JAMBU METE DI DESA BANTEA KECAMATAN GU KABUPATEN BUTON TENGAH
}

\section{La Ode Muhammad Mustari}

\author{
Program Studi Agribisnis Fakultas Peranian \\ Universitas Muhammadiyah Buton \\ Jin. Betoambari No. 36 Baubau \\ e-mail : $\underline{\text { Imnnistari74@yahoo.co.id }}$
}

\begin{abstract}
The study discusses about economic social characteristic influence to production of Jambu mete in Bantea Village, Subdistrict of Gu Central Buton Regency. This study discusses the influence of socio-economic characteristics of the production of cashew in Bantea Village, Subdistrict of Gu Central Buton Regency. This study was conducted over three months starting in June until August 2015. The population of this research is that there are cashew farmers, sample taking by the number 28 cashew farmers. Data were collected through interviews using a questionnaire and analyzed using descriptive analysis. From the results of the study concluded that the cashew nut farmers in Bantea Village, Subdistrict of Gu Central Buton Regency shows that socioeconomic factors (education, farming experience, number of dependents and land) significantly affected the production of cashew nut farmers. By him it was suggested to farmers, is expected to further enrich the knowledge and insights of the farming handled, especially in terms of the handling of pests and plant diseases, and the government is expected to give more attention to farmers, whether it be the handling of low production due to high rainfall and plant pests and diseases.
\end{abstract}

Keywords: production, socio-economic, cashew.

\begin{abstract}
Abstrak
Penelitian ini membahas pengaruh karakteristik sosial ekonomi terhadap produksi jambu mete di Desa Bantea Kecamatan GU Kabupaten Buton Tengah. Penelitian ini dilaksanakan selama tiga bulan dimulai pada bulan juni sampai agustus 2015. Populasi dari penelitian ini adalah petani jambu mete yang ada, sampel penelitian mengambil dengan jumlah 28 orang petani jambu mete. Data dikumpulkan melalui wawancara dengan menggunakan daftar pertanyaan dan dianalisis dengan menggunakan analisis deskriptif. Dari hasil penelitian disimpulkan bahwa petani jambu mete di Desa Bantea Kecamatan GU Kabupaten Buton Tengah diperoleh bahwa faktor sosial ekonomi (tingkat pendidikan, pengalaman bertani, jumlah tanggungan keluarga dan luas lahan) berpengaruh nyata terhadap produksi petani jambu mete. Olehnya itu disarankan kepada petani, diharapkan lebih memperkaya pengetahuan dan wawasannya tentang usahatani yang dikelolannya, terutama dalam hal penanganan hama dan penyakit tanaman serta pemerintah diharapkan memberikan perhatian lebih kepada petani, baik itu berupa penangganan produksi yang rendah akibat curah hujan yang tinggi maupun hama penyakit tanaman.
\end{abstract}

Kata kunci: produksi, sosial ekonomi, jambu mete.

PENDAHULUAN 
Jambu mete (Anacardium occidentale L.), merupakan salah satu komoditas yang mendapat prioritas dalam pembangunan perkebunan dewasa ini, terutama di Kawasan Timur Indonesia (KTI). Tujuan pokok usahatani jambu mente saat ini adalah mendapatkan produksi dan kualitas gelondong setinggi-tingginya agar mampu memberikan pendapatan pada petani seoptimal mungkin. Di KTI komoditas ini memberikan peluang yang besar bagi pengentasan kemiskinan, karena pada umumnya di kawasan ini sebagian besar berlahan kering (Abdullah, 1995) dalam (Hadad E.A dan Koemiati, 1996). Provinsi Sulawesi Tenggara merupakan salah satu daerah yang memiliki potensi sumberdaya pertanian dan agroklimat yang sesuai untuk pengembangan tanaman jambu mete. Potensi jambu mete di Sulawesi Tenggara tersebar di 12 daerah kabupaten/kota yang diusahakan dalam bentuk perkebunan rakyat. Areal tanaman jambu mete yang menghasilkan di Provinsi Sulawesi Tenggara pada tahun 2009 seluas 117.031,6 ha dengan produksi 26.448,9 ton biji mete gelondongan kering (Badan Pusat Statistik Sulawesi Tenggara, 2011).

Berdasarkan data luas lahan dan produksi, diketahui bahwa secara ekonomi tanaman jambu mete merupakan salah satu potensi sumber pendapatan utama bagi petani di Sulawesi Tenggara. Produksi mete gelondongan kering yang dihasilkan dapat dijadikan sumber bah an baku bagi usaha pengolahan kacang mete. Melalui kegiatan pengolahan tersebut diharapkan mampu memberikan nilai tambah yang signifikan bagi petani pengolah, sehingga petani mampu meningkatkan pendapatan keluarga. Hasil penelitian Indrawanto et al. (2003) mengenai faktor-faktor yang mempengaruhi keberhasilan usahatani jambu mete di Sulawesi Tenggara, menyimpulkan bahwa prioritas pembangunan usahatani jambu mete yang tangguh di Sulawesi Tenggara adalah peningkatan kekuatan modal petani melalui pola pendanaan ekstemal dari perbankan dengan persyaratan mudah dan bunga yang lunak, serta peningkatan teknologi budidaya jambu mete melalui penerapan teknik budidaya yang spesifik lokasi. Selain itu, diperlukan pengembangan industri pengacipan di lokasi sentra produksi mete untuk memperluas pasar mete bagi petani. Kabupaten Buton merupakan salah satu daerah sentra produksi jambu mete di Provinsi Sulawesi Tenggara. Tanaman jambu mete diusahakan di 19 kecamatan dari 21 kecamatan yang berada di Kabupaten Buton. Produksi jambu mete di Kabupaten Buton pada tahun 2009 sebesar 7.208 ton dimana $2.456,73$ ton atau $34,08 \%$ dari jumlah produksi tersebut dihasilkan petani jambu mete di Kecamatan Gu dan Lakudo (Badan Pusat Statistik Kabupaten Buton, 2011).

Dari penjabaran di atas menunjukan bahwa desa Bantea Kecamatan GU Kabupaten Buton Tengah merupakan sentra penghasil jambu mete dengan luas tanam, luas panen dan produksi yang telah memberikan kontribusi bagi sektor pertanian.

Untuk mengetahui luas lahan, luas tanam dan produksi jambu mete di desa Bantea Kecamatan GU Kabupaten Buton Tengah dapat dilihat pada Tabel 1 berikut: 
Tabel 1. Luas tanam, Luas panen dan produksi Jambu Mete di Kecamatan GU Kabupaten Buton Tengah Tahun 2012-2014.

Tahun Luas Tanam (Ha) Luas Panen (Ha) Produksi (Kw/Ha)

\begin{tabular}{llll}
\hline Tahun 2012 & 2.336 & 2.051 & 425 \\
\hline Tahun 2013 & 2.486 & 2.406 & 529 \\
\hline Tahun 2014*) & 2.386 & 2.223 & 505
\end{tabular}

Sumber Data : BPS Buton, 2014 *) Dinas Pertanian Kabupaten Buton, 2014.

Kendala usahatani jambu mete yang dirasakan petani di Desa Bantea adalah rendahnya produksi dan nilai pendapatan petani, tanaman yang sudah tua, keterbatasan pengetaiiuan petani, keterbatasan lahan yang dimiliki petani dan posisi penawaran pada pihak petani yang kurang kuat. Hal tersebut menyebabkan rendahnya nilai keuntungan yang diperoleh petani. Melihat keadaan tersebut berarti ada kenyataan dan harapan, maka dirasa perlu diadakan penelitian lebih lanjut tentang beberapa faktor sosial ekonomi yang mempengaruhi produksi dan pendapatan petani jambu mete di desa Bantea Kecamatan GU Kabupaten Buton Tengah.

Berdasarkan uraian latar belakang maka diidentifikasi beberapa masalah yaitu : Apakah faktor sosial ekonomi (tingkat pendidikan, pengalaman bertani, jumlah tanggungan keluarga dan luas lahan) berpengaruh nyata terhadap produksi petani jambu mete di desa Bantea Kecamatan GU Kabupaten Buton Tengah?

\section{METODE PENELITIAN}

Penelitian ini dilakukan di Desa Bantea Kecamatan GU Kabupaten Buton Tengah yang dilaksanakan pada bulan Juni - Agustus 2015, dengan pertimbangan desa tersebut merupakan salah satu sentra produksi jambu mete dan daerahnya mudah dijangkau oleh peneliti. Populasi dari penelitian ini adalah petani yang melakukan usahatani jambu mete yang ada di Desa Bantea Kecamatan GU Kabupaten Buton Tengah. Penarikan sampel penelitian mengambil $20 \%$ dari total petani 120 orang. Menurut Sugiyono (1998) jika populasi diatas 100 orang maka dapat dilakukan sampel 20\%-30\%, namum jika populasi dibawah 100 orang maka dilakukan sampel seluruhnya. Sehingga dari 120 petani jambu mete yang menjadi sampel adalah 28 orang.

Data yang dikumpulkan adalah data primer dan data sekunder. Data primer diperoleh melalui wawancara langsung dengan menggunakan kuesioner. Sedangkan data sekunder merupakan data pelengkap yang diperoleh dari berbagai instansi dan lembaga yang terkait dengan penelitian ini. Data yang diperoleh dari penelitian ini ditabulasi selanjutnya dianalisis secara deskriptif kuantitatif. Dimana analisis yang digunakan adalah analisis regresi linier berganda dengan menggunakan teknik korelasi product moment dengan program SPSS 19.0 for windows.

Produksi lahan sebagai variabel terikat, sedangkan tingkat pendidikan, pengalaman bertani, jumlah tanggungan keluarga dan luas lahan sebagai variabel bebas. Rumus yang digunakan adalah :

$Y=a+b_{1} X_{1}+b_{2} X_{2}+b_{3} X_{3}+b_{4} X_{4}$ 
(Hasan, 2002)

Dimana:

$\mathrm{Y}=$ Produksi lahan $(\mathrm{kg} / \mathrm{ha})$

$\mathrm{a}=$ parameter intercept

$\mathrm{b}_{1}, \mathrm{~b}_{2}, \mathrm{~b}_{3}, \mathrm{~b}_{4}=$ parameter koefisien regresi

$\mathrm{X}_{1}=$ tingkat pendidikan (tahun)

$\mathrm{X}_{2}=$ pengalaman bertani (tahun)

$\mathrm{X}_{3}=$ jumlah tanggungan keluarga (jiwa)

$\mathrm{X}_{4}=$ luas lahan $(\mathrm{Ha})$

Untuk menguji pengaruh pengaruh variabel bebas secara serempak terhadap produksi, digunakan uji $\mathrm{F}$ dengan kriteria uji sebagai berikut:

Jika $\mathrm{F}_{\text {hitung }}<\mathrm{F}_{\text {tabei }}$ : maka terima $\mathrm{H}_{0}$ atau tolak Hi

Jika $F_{\text {hitung }}>F_{\text {tabel }}$ : makaterima Hi atau tolak Ho .

\section{PEMBAHASAN}

Pengaruh Faktor Sosial Ekonomi terhadap Produksi dan Pendapatan Jambu Mete di Desa Bantea Kecamatan Gu Kabupaten Buton Selatan

Hasil analisis dapat dilihat pada Tabel 2 berikut:

Tabel 2. Pengaruh Faktor Sosial Ekonomi terhadap Produksi Jambu Mete di Desa Unstandardized Standardized

Model Coefficients Coefficients $\mathrm{T} \quad$ Sig.

\begin{tabular}{|c|c|c|c|c|c|}
\hline & & & & & \\
\hline & B & Std. Error & Beta & & \\
\hline (Constant) & 36,573 & 59,117 & & 4,619 & ,000 \\
\hline $\begin{array}{l}\text { XI (Tingkat } \\
\text { Pendidikan) }\end{array}$ & 4,456 & 4,539 &, 040 & ,982 & ,004 \\
\hline $\begin{array}{l}\text { X2 (Pengalaman } \\
\text { Bertani) }\end{array}$ & 2,476 & 2,402 &, 050 & 1,031 & ,002 \\
\hline $\begin{array}{l}\text { X3(Jumlah } \\
\text { Tanggungan) }\end{array}$ & $-4,394$ & 9,114 &,- 023 &,- 482 & ,004 \\
\hline X4 (Luas Lahan) & & & & & \\
\hline $\mathrm{R}^{2}=0,966$ & & & & & \\
\hline$F_{\text {hitung }}=189,495$ & 37,430 & 1,600 & ,979 & 23,392 &, 000 \\
\hline$F_{\text {tabel }}=2,60$ & & & & & \\
\hline$t_{\text {tabel }}=2,04$ & & & & & \\
\hline
\end{tabular}

Sumber : Analisis data SPSS versi 19.0 
Model regresi yang diperoleh adalah :

$\mathrm{Y}=36,573+4,456 \mathrm{x},+2,476 \mathrm{x}_{2}-4,394 \mathrm{x} 3+37,430 \mathrm{x} 4$

Dari model di atas diperoleh interprestasi sebagai berikut:

1. Setiap terjadi peningkatan tingkat pendidikan selama setahun, terjadi pula peningkatan produksi sebesar 4,456 kg. Ini berarti bahwa Semakin tinggi tingkat pendidikan petani, menunjukan bahwa dalam menjalankan usahatani jambu mete petani lebih berhati-hati dalam mengambil sebuah keputusan dan cenderung mempertimbangkan segala macam resiko yang bakal dihadapi. Sementara tingkat pendidikan petani yang rendah bisa menjadi faktor penghambat dalam mengakses informasi dan teknologi baru yang berkaitan dengan usahatani yang dijalankan. Hal ini pula diperkuat dengan hasil wawancara dengan petugas penyuluh yang menyatakan mayoritas petani jambu mete mempunyai tingkat pendidikan yang masih minim yang berimbas pada peningkatan produksi jambu mete.

2. Setiap terjadi peningkatan pengalaman bertani selama setahun, terjadi pula peningkatan produksi sebesar 2,476 kg. Hal ini disebabkan oleh Petani yang memiliki pengalamaan berusahatani di atas 20 tahun umumnya berusia di atas 50 tahun bahkan sebagian besar adalah petani yang kurang produktif akibat usia yang semakin tua. Ini pula dipertegas oleh petugas penyuluh yang menyatakan bahwa mayoritas petani jambu mete mempunyai pengalaman berusahatani rata-rata 23 tahun sehingga mempengaruhi tingkat produksi jambu mete

3. Setiap terjadi peningkatan jumlah tanggungan keluarga selama setahun, terjadi pula penurunan produksi sebesar 4,394 $\mathrm{kg}$. Ini menunjukan bahwa rata-rata jumlah tanggungan keluarga petani jambu mete adalah 5 orang artinya besar kecilnya jumlah anggota keluarga yang menjadi tanggungan seorang kepala keluarga berkaitan dengan besar kecilnya biaya yang akan dikeluarkan oleh kepala keluarga tani dalam memenuhi kebutuhan hidup sehari-hari. Semakin besar jumlah tanggungan dalam keluarga, semakin besar pula biaya yang harus dikeluarkan untuk memenuhi kebutuhan hidup sehari-hari.

4. Setiap terjadi peningkatan luas lahanselama setahun, terjadi pula peningkatan produksi sebesar 37,430 kg. Ini berarti bahwa semakin luas lahan yang diusahakan oleh petani jambu mete akan mempengaruhi produksi. Hal ini pula diperkuat oleh pemyatan Ashari, 1995 menyatakan bahwa luas lahan pertanian sebagai asset penting yang dimiliki petani sangat menentukan peluang berusaha bagi dirinya. Asset ini berpengaruh terhadap besamya pendapatan yang mereka peroleh dari pengelolaan di atas lahan tersebut. Lahan yang sempit tentu saja membuat hasil yang diperoleh tidak memadai sehingga pendapatan yang mereka peroleh juga rendah.

Dari hasil regresi diperoleh $\mathrm{R}^{2}$ sebesar 0,966 Hal ini berarti faktor sosial ekonomi hanya memberikan pengaruh sebesar $96,60 \%$ saja, sisanya dipengaruhi oleh faktor lain yang tidak dibahas dalam penelitian ini.

Dari hasil uji F dihasilkan Fhitung sebesar 189,495 (lebih kecil dari $F_{\text {tabel }}=2,60$ ) dengan signifikasi sebesar 0,000 (lebih besar dari a =0,05). Sehingga dapat disimpulkan bahwa Hi diterima dan Ho ditolak, bahwa faktor sosial ekonomi secara serempak berpengaruh nyata terhadap produksi petani jambu mete. Ini menunjukan bahwa karakteristik sosial ekonomi sangat berpengaruh nyata terhadap produksi jambu mete di lokasi penelitian hal ini beralasan karena mayoritas daerah penelitian adalah petani jambu mete yang telah lama berusahatani jambu mete serta selalu menerima inovasi tentang teknik budidaya jambu mete dari petugas penyuluh. 
Hal ini sesuai pandangan oleh Kepala Pertanian Kecamatan Gu mengatakan bahwa para petani jambu mete mayoritas telah optimal melakukan budidaya jambu mete dengan baik dan rata-rata memiliki lahan 1,63 ha sehingga diperkirakan akan memproduksi rata-rata $189 \mathrm{~kg} / \mathrm{ha}$ (Wawancara dengan La Ana., tanggal 16 Juli 2015).

Ini pula diperkuat pandangan Menurut Mosher (1981), mengatakan bahwa latar belakang sosial ekonomi dan budaya ataupun politik sangat mempengaruhi cepat lambatnya suatu inovasi dapat diterima oleh petani. Beberapa faktor penting mempengaruhi penerapan inovasi adalah sebagai berikut: umur, pendidikan, dan keberanian mengambil resiko, pola hubungan masyarakat dengan dunia luar dan sikap terhadap perubahan.

\section{KESIMPULAN DAN SARAN}

\section{Kesimpulan}

Berdasarkan keseluruhan uraian hasil penelitian, maka dapat disimpulkan sebagai berikut:

1. Faktor sosial ekonomi (tingkat pendidikan, pengalaman bertani, jumlah tanggungan keluarga dan luas lahan) berpengaruh nyata terhadap produksi petani jambu mete.

2. Dari hasil regresi diperoleh $\mathrm{R}^{2}$ sebesar 0,966 Hal ini berarti faktor sosial ekonomi berpengaruh nyata sebesar $96,60 \%$ saja, sisanya dipengaruhi oleh faktor lain yang tidak dibahas dalam penelitian ini.

\section{Saran} berikut:

Bertolak dari hasil penelitian tersebut, maka dapat disarankan adalah sebagai

1. Kepada petani, diharapkan lebih memperkaya pengetahuan dan wawasannya tentang usahatani yang dikelolanya, terutama dalam hal penangganan hama dan penyakit tanaman serta alternatif tanaman lain dalam upaya menambah usahatani.

2. Kepada pemerintah diharapkan memberikan perhatian lebih kepada petani, baik itu berupa penangganan produksi yang rendah akibat curah hujan yang tinggi maupun hama penyakit tanaman. Selain itu pelatihan dan penyuluhan tentang budidaya tanaman jambu mete perlu ditingkatkan kembali.

\section{DAFTAR PUSTAKA}

Alauddin, 1996. Status dan Pengembangan Nasional Komoditas Jambu Mente di Indonesi. Prosiding. Forum Komunikasi Ilmiah Komoditas Jambu Mente. Tanggal 5-6 Maret 1996. Balai Penelitian Tanaman Rempah dan Obat. Bogor.

Badan Pusat Statistik. 2006. Statistik Perkebunan Indonesia 2003 - 2005. Dirjen Perkebunan. 2006. Jakarta.

Badan Pusat Statistik. 2011. Statistik Perkebunan Indonesia 2011. Kendari.

Hadad, E. A. Dan Koerniati. 1996. Sambung Pucuk Sebelas Nomor Harapan Jambu Mete Langsung di Lapang. Prosiding. Forum Komunikasi Ilmiah Komoditas Jambu Mente. Tanggal 5 - 6 Maret 1996. Balai Penelitian Tanaman Rempah dan Obat. Bogor.

Hermanto dan Zaubin, R. 2001. Persyaratan Lingkungan Tumbuh Jambu Mente. Monograf Jambu Mente. Balai Penelitian Tanaman Rempah dan Obat. Bogor. 
Krisnamurthi, B. 2001 Agribisnis. Yayasan Pengembangan Sinar Tani. Bahan Kuliah. Jurusan Ilmu-Ilmu Sosial Ekonomi Pertanian. Fakultas Pertanian. Institut Pertanian Bogor.

Kasmir dan Jakfar. 2007. Studi Kelayakan Bisnis. Edisi Kedua, Cetakan Ke-4. Kencana. Jakarta.

Lipsey et all. 1995. Pengantar Mikroekonomi. Binarupa Aksara. Jakarta.

Mubyarto. 1989. Pengantar Ekonomi Pertanian. Edisi Ketiga. LP3ES. Jakarta.

Nogoseno. 1996. Pengembangan Jambu Mente di Indonesia. Prosiding. Forum Komunikasi Ilmiah

Komoditas Jambu Mente. Tanggal 5-6 Maret 1996. Balai Penelitian Tanaman Rempah dan Obat. Bogor.

Nazir, Moh. 2003. Metode Penelitian. Ghalia Indonesia. Jakarta.

Rosman dan Lubis. 1996. Aspek Lahan dan Iklim Untuk Pengembangan Tanaman Jambu Mente. Presiding. Forum Komunikasi Ilmiah Komoditas Jambu Mente. Tanggal 5 - 6 Maret 1996. Balai Penelitian Tanaman Rempah dan Obat. Bogor.

Rosmeilisa, P. 1990. Pola Usahatani Tanaman Jambu Mete. (Studi Kasus Kabupaten Bantul dan Kabupaten Gunung Kidul Daerah Istimewa Yogyakarta). Perkembangan penelitian Tanaman Jambu Mente. Edisi Khusus Litro Vol. 21990 Balai Penelitian Tanaman Rempah dan Obat. Bogor.

Rosmeilisa, P. dan Yuhono, JT. 2001. Ana!isis Usahatani Jambu Mente. Monograf Jambu Mente. Balai Penelitian Tanaman Rempah dan Obat. Bogor.

Rosmeilisa, P. dan Abdullah, A. 1990. Analisis Usahatani Jambu Mente. Perkernbangan penelitian Tanaman Jambu Mente. Edisi Khusus Litro Vol. 21990 Balai Penelitian Tanaman Rempah dan Obat. Bogor.

Sukmadinata, T. 1996. Prospek Pengembangan Agribisnis Jambu Mente di Indonesia. Prosiding. Forum Komunikasi Ilmiah

Komoditas Jambu Mente. Tanggal 5 - 6 Maret 1996. Balai Penelitian Tanaman Rempah dan Obat. Bogor.

Saragih, YP. Dan Haryadi, Y. 1994.

Mete. Budidaya Jambu Mente, Pengupasan Gelondong. Penebar Swadaya. Jakarta.

Sukartawi. 1996. Agribisnis Jambu Mente. Prosiding. Forum Komunikasi Ilmiah Komoditas Jambu Mente. Tanggal 5-6 Maret 1996. Balai Penelitian Tanaman Rempah dan Obat. Bogor.

Soeharjo, A. dan D. Patong. 1973. Sendi-Sendi Pokok Ilmu Usahatani. Departemen IlmuIlmu Sosial Ekonomi Pertanian. Fakultas Pertanian. Institut Pertanian Bogor. Bogor. 